Journal of Digitovation and Information System

http://jdiis.de/index.php/jdiis

\title{
Antecedents and Outcomes of Innovation Capability: A Case of European Automotive Organizations
}

\author{
Akhlaq Ahmad* \\ Faculty of Computer Science, University of Dunaujvaros, Dunaujvaros, Hungary
}

\section{Abstract}

Most of the firms are keen to achieve desired performance levels and competitive advantage through creativity and innovation. Thus, drawing on the resource-based view current study aims to contribute by exploring the underlying mechanism through which firms' characteristics are linked with firm performance and competitive advantage. Using online survey data was collected from 303 managers from German and Italian SMEs, results revealed that innovation capability mediated the associations between antecedents (creativity \& dynamic capability) and outcomes (competitive advantage and performance). Several key policy insights and future research directions are suggested.

Keywords

Dynamic Capability; Creativity; Innovation Capability; Performance;

Competitive Advantage

\section{Introduction}

Understanding the anatomy of competitive advantage is paramount to general managers who bear the ultimate responsibility for a firm's long-term survival and success. In today's global world, sustaining competitive advantage and maintaining a firm's performance has become highly difficult. The internet and other technological advancements have made companies worldwide interdependent on resources and vulnerable to competition from the external and international environment (Kryscynski et al., 2021). These environments are highly complex, continuously changing, and evolving as companies' battle for resource management regarding employees' skills, knowledge, creativity, and innovation to stay ahead of their competitors (Hagiu \& Wright, 2020). This study is focused on identifying factors leading to a firm's competitive advantage and performance achievement.

Competitive advantage is one of the measures of success for companies, and companies strive their best to gain it. It refers to a unique resource to a company or organization, such that it is rare, valuable, inimitable, non-tradable, and nonsustainable while being firm-specific (Miotto et al., 2020). Competitive advantage creates a defensible position in the market for a company. It is sustainable against direct and indirect competition faced by the company regarding its resources, revenue generation, customer base, and market returns (Yasa et al., 2020). It is highly context-specific since each industry has its challenges, regulations, resources, and various stakeholders, and dynamic external and internal environment. Therefore, in this study, we will explore how various firm capabilities impact it.

Although various studies previously have examined competitive advantage as a leading factor towards firm performance. But this study is unique as it investigates performance separate and independent from competitive advantage and rather based on other factors such as firms' creativity, dynamic capabilities, and innovative capabilities that have not been explored previously. Moreover, organizational performance is usually measured in financial performance ratios such as return on assets and sales growth ratio (Nukunudompanich et al., 2020). Although in this study we will investigate it in terms of market-based performance that refers to aligning organizational resources towards the achievement to organizational goals and ambitions that are achieved through proper management, productivity, engagement and motivation, and retention and loyalty of employees that are a source of creativity and innovation for the firm (Jabri et al., 2020). Organizational goals and ambitions are achieved through proper management, productivity, engagement, and motivation, and the retention and loyalty of employees are a source of creativity and innovation for the firm (Jabri et al., 2020). To support work from home in the current pandemic, analytics through digitization utilizing Big Data, and artificial intelligence and machine learning (Hanelt et al., 2021). 
One of the important factors that also makes this study unique and highly fundamental is the role of innovation capability of the firm that is explored in terms of its mediating role for gaining competitive advantage and achieving the firm's performance which has not been explored previously. Innovation capability refers to a firm's ability to identify new ideas and transform them into new products, services, and processes that can benefit the firm (Bocken \& Geradts, 2020). Innovation has always been considered a vital ingredient for a firm's competitive advantage as it enables companies to produce unique, new, and changing ideas that help them stay ahead of the game (Wang et al., 2021). It is formulated based on originality, concoction, and the construction of unique ways to approach existing problems and needs in the marketplace (Chivandi et al., 2020). Hence, in this study, we will explore how an organization's innovation capability mediates between its dynamic capabilities, creativity, competitive advantage, and performance.

Another critical and contributing factor towards achieving a firm's competitive advantage and maintaining its performance levels is the dynamic capabilities. Dynamic capabilities refer to the organization's capabilities to optimally and purposefully adapt towards its external and internal environment for building its resource base (Bocken \& Geradts, 2020). It includes organizational and strategic routines that the firm utilizes to formulate resources that can configure market changes and demands (Suddaby et al., 2020). This study is vital as we explore the role of dynamic capabilities of the firm to contribute towards creativity leading towards competitive advantage and firm performance that have not previously been focused on.

Creativity has always been thought to be an important ingredient and antecedent of a firm's competitive advantage. It is the phenomenon that uses the imagination of employees to create something new and valuable that might be intangible or a physical object (Schutte \& Malouff, 2020). Furthermore, it refers to the company's tendency to generate and recognize ideas, alternatives, and possibilities for existing problems or creating new needs in the market for the customer (Ismoilov, 2020). Creativity is enhanced in a supportive environment, and the organization focuses on working on the knowledge capital of its employees. Hence, in this study, we will explore how creativity impacts the firm's innovation capability to achieve competitive advantage and maintenance of performance.

Europe is considered a hub of giant economies based on literacy rate, multibillionaire organizations and businesses, technology advancement, and a high standard of life for its residents (Beaty \& Johnson, 2020). Many giant industries contribute to exports, GDP, and economic growth in Europe; one such industry is the automotive industry that we will explore in this study. This study focuses on automotive organizations of Germany and Italy to investigate how they are sustaining competitive advantage and performance standards in the highly evolving competitive environment. Germany is one of the major players in the automotive industry, and in 2019 it exported roughly 17.8 billion tons of cars for an export value of approximately 217.8 around various countries (Analytica, 2021). Based on volume production, Italy was declared the seventh-largest automobile manufacturer in Europe in 2019 (Frasson, 2020).

The theoretical foundation is based on the resource-based view, commonly known as RBV of strategic management theory, that advocates that a firm possesses and controls certain unique resources and capabilities which makes it different from other firms, creates competitive advantage, and contributes to its performance (Khana et al., 2020). Furthermore, it argues that unique and valuable resources can lead to creating a firm's competitive advantage; hence, in this study, we will explore how the firm's dynamic capabilities, creativity, and innovation capability lead to its competitive advantage and improve its competitive advantage performance.

This study is highly significant since it explores how the automotive industry sustains a competitive advantage in challenging times. First, this study explores the mediating role of innovation capability and contributes to literature for its impact on organization dynamic capabilities, creativity, firm performance, and competitive advantage. Then this study explores the role of firms' dynamic capabilities and how they affect achieving competitive advantage and performance which has hardly been explored before. Finally, this study is vital in utilizing RBV to explain how a firm's resources and capabilities contribute to achieving and maintaining competitive advantage and performance.

\section{Literature review and research framework}

\subsection{Theoretical foundation}

This study follows the theoretical foundation of resource-based view theory known as RBV developed by Barney (1986), which Werner felt first introduced in 1984, (Galbreath, 2005). It suggests that a firm is defined by the resources it integrates, and therefore each firm is unique based on the resources it possesses in terms of raw material, assets, human capital, and human resources (Lin \& Wu, 2014). Based on this assumption, firms can outperform others to gain a competitive advantage by transforming these resources into something unique that can benefit the firm (Duarte et al., 2014). Examples of resources are brand names, in-house knowledge of technology, skilled personnel, trade contacts, machinery, efficient procedures, and capital. There are two major assumptions of RBV; the first assumption is that each organization (regardless of its size) is formulated on resource heterogeneity of tangible and intangible assets (e.g., competencies, and capabilities). And second is based on resource immobility that some resources such as intangible ones including organizational capabilities are difficult to imitate by the competitors and are often irreplaceable (Ruivo et al., 2016). 
In our study context, the firm resources are studied in terms of dynamic capabilities, creativity, and innovation capabilities that lead to the firm's competitive advantage and improve the firm's performance. This theory also suggests that competitive advantage is context-specific (Gisip \& Harun, 2013). Therefore, the environment in which the company operates, industry requirements and regulations, target market, and technological changes greatly impact and determine how companies sustain competitive advantage. Therefore, this study will explore how companies' innovation and dynamic capabilities can help achieve competitive advantage and sustained performance.

\subsection{Relationship between dynamic capability - Innovation capability, creativity}

Literature suggests that dynamic capabilities are underpinned by organizational routines and managerial skills that adhere to and address changes in the business environment (Reilly \& Tushman, 2008). Dynamic capabilities enable the firm to adapt, integrate, and build internal competencies that can respond to evolving market conditions (García \& Velasco, 2004). Dynamic capabilities are idiosyncratic and unique to each company's culture and history (Zott, 2003). Therefore they are linked to ability, capacity, competence, capability, resource, resource base, process, and routine (Helfat, 1997). At the same time, innovation capability is linked to the generation of new ideas and processes to better adapt to external changes and compete in the industry (Swink, 2006). Research shows that innovation capability is based upon a strong technological and information system that utilizes high-quality open resources to transform employees' skills into profitable products (Guan \& Ma, 2003). Studies also emphasize that innovation capability must be viewed along two dimensions, innovation novelty and market characteristics, as these two factors enable and set the basis for a firm to transform its knowledge base into innovative ideas and processes explicitly (Sher \& Yang, 2005; Weerawardena, 2003a). Hence, we can propose that,

H1: Dynamic capability is positively associated with innovation capability.

H2: Dynamic capability is positively associated with creativity.

\subsection{Relationship between creativity and innovation capability}

Creativity is often interchangeably used with innovation, whereas research shows that creativity relates to a vital form of intelligence that drives people to discover something new. Innovation relies on introducing change into relatively stable systems (Amabile et al., 2005). Innovation is related to making an idea viable and profitable to the organization to serve the interests of its stakeholders best, usually through the incorporation of technology (Stojcic et al., 2018). Previous studies advocate that knowledge management is a vital part of innovation (Bharadwaj \& Menon, 2000; Gunday et al., 2011). As creativity relies on building something original that can represent an idea, it is usually hard to imitate (Kaufman, 2016). Therefore, innovation is more specifically the application of creativity as it is based on new and unique ideas (Kaufman et al., 2008). The previous literature indicates that entrepreneurship is based on the creativity and innovative capability of the firm to sustain innovation over time, in returning gaining competitive advantage (Weerawardena, 2003b). A firm's innovative capability is associated with renewal and firm performance to maintain flexibility towards rapid changes occurring in an external environment (Slater et al., 2014). Hence, we can propose that,

H3: Creativity is positively associated with innovation capability.

\subsection{Relationship between innovation capability and competitive advantage}

Previous research indicates that innovative capability leads to an organization's development through implementing strategies, systems, and structures that support innovation in an organization (Cavusgil et al., 2003). Research also suggests that innovation capability is a critical source for a firm's success and survival in a competitive environment that relies on the intellect of human capital within the organization (Guan \& Ma, 2003). Innovation is also a basic ingredient of change and evolution as it enables companies to revisit existing systems and processes being carried for the manufacturing of products (Lawson \& Samson, 2001). This helps companies achieve efficiency by improving existing services by introducing innovative technologies that reduce the cost and time previously exerted on products. Hence, innovative capability can lead to new business thinking processes that generate and reform unconventional and flexible operations (Connor, 2008). Competitive advantage is attained through continuously improving processes, products, and services through innovation (Ireland et al., 2002). Previous literature shows that competitive advantage is dependent upon cost structure, branding, the quality of product offerings, intellectual property, and customer services (Hinterhuber, 2013). Hence, based on this discussion, we can suggest that innovative capability positively impacts companies to achieve their competitive advantage.

H4: Innovation capability is positively associated with a competitive advantage.

\subsection{Relationship between innovation capability and firm performance}

Research has found that innovation structure and innovation culture help improve firm innovation performance. A 
firm's performance is based on achieving strategic goals, productivity, sales targets, and employee motivation to continuously improve services and products (Bocken \& Geradts, 2020). Literature suggests that capabilities enable firms to seek change and innovation to sustain existence in complex work environments (Haldma et al., 2012). Studies suggest that entrepreneurs are usually linked and found to be agents of change for managing knowledge resources leading to innovation capabilities (Gunday et al., 2011; Sher \& Yang, 2005). These capabilities are utilized to develop new goods and produce them on a commercial matter. Research also indicates that each firm is a result of technological synthesis which lays the foundation of business relations (Gong et al., 2013). The firm's performance is based on technological and business efficiency and effectiveness, as technology leads to innovation relating to new products and subsequent production (A. Anderson \& Gupta, 2009). It is based upon development capability and operations capability (Zott, 2003). According to RBV theory, firms that can strengthen their capabilities to achieve strategic goals are better able to sustain performance ( Kaufman, 2015).

H5: Innovation capability is positively associated with firm performance.

\subsection{The mediating role of innovation capability between dynamic capability and competitive advantage}

Literature suggests that dynamic capability has the greatest explanatory power when a partially foreseeable technological change is on the verge of transforming market competition (Tseng \& Lee, 2014). The dynamic capability has been studied regarding the effect size of capabilities, industry in which the company operates, Technological shifts, and if the change can be approximated and forecasted (Bowman \& Ambrosini, 2003). Dynamic capabilities are based upon resources, capabilities, and strategies vital for attaining competitive advantage (Helfat, 1997). They are developed by sensing, seizing, and transforming organization needs into profitable opportunities to increase their value (Newbert, 2005). The firm's inherent capability to optimally and purposefully adapt, modify, and enhance organizational resource base (Vogel \& Güttel, 2013). Competitive advantage is related to price, location, selection, speed, turnaround, and service (Cockburn et al., 2000). It has also been linked and attributed to cost leadership, differentiation, defensive strategies, and strategic alliance (Porter \& Kramer, 2002). Research also supports that dynamic capabilities lead to competitive advantage based on RBV assumption as these dynamic capabilities are hard to replicate and are unique to each firm's internal operations (Somsuk et al., 2012).

Innovation capability has been linked to product innovation, flexibility, and adaptation (Chivandi et al., 2020). Innovation capability has been considered important in developing and adapting new products to satisfy market needs (Jantunen, 2005). On the other hand, dynamic capability affects the corporate reputation, environmental insight, and resource integration capability of the firm (García \& Velasco, 2004). The dynamic capability allows firms to build upon strong and reliant resources that help firms achieve competitive advantage (Vogel \& Güttel, 2013). Firms need to constantly monitor, enhance, and utilize their innovation to sustain and transform into a vital resource that can help maintain a competitive advantage for the company (Belderbos et al., 2004). Especially in the automobile industry, it is found that more or less the processes being same the firms are relying on innovative capabilities to enhance processes and deliver unique features for the customers to differentiate their products and ultimately gain competitive advantage (Iansiti \& Clark, 1994). The firm's dynamic capabilities also allow them to stay ahead of changes occurring in its environment and reduce risks associated with these rapid occurring changes (Sanchez, 2008). Hence, we can propose that,

H6: Innovation capability mediates the relationship between dynamic capability and competitive advantage.

\subsection{The mediating role of innovation capability between dynamic capability and firm performance}

Scholars have argued that dynamic capability can influence firm performance through various means and mechanisms (Iansiti \& Clark, 1994; Menguc \& Auh, 2006). Studies have linked dynamic capability with marketing and operations for new product development and firm performance (Jantunen, 2005; Connor, 2008). Previous literature also supports that firm performance is enhanced in the firm's presence of adequate dynamic capabilities (Vogel \& Güttel, 2013). Dynamic capabilities are idiosyncratic and unique to each company's culture and history (Danneels, 2011). Research advocates that dynamic capabilities are essential for the company's long-term growth (Makadok, 2001). They are related to the organization's capacities to create new products and services in response to evolving market conditions. Firm performance is based on intangibles, corporate governance, cash on hand, leverage, firm-specific risk, size growth, and tangibility (Gunday et al., 2011). Previous research indicates that performance differences between firms are attributed to organizational factors such as routines, knowledge, and strategies implemented to improve organizational functions and processes (Dyer, 2006). Various factors play role in affecting organizational performance such as stakeholders, heterogeneous market circumstances, and time required to create value (Kaufman, 2015). Some scholars hold that dynamic capability is one of the keys to achieving competitive advantage and performance in strategic management (Makadok, 2001). In terms of dynamic capability in the strategic process, they have been investigated previously in terms of the potential to systematically solve problems, sense opportunities, and threats, and make timely decisions to implement strategies for countering change (Danneels, 2011). Innovation competencies have been linked to affecting the firm's performance based 
on the firm's management (Tseng \& Lee, 2014). Innovation capabilities provide stability and risk assurance to maintain the seamless functioning of organizational factors (Gisip \& Harun, 2013). Firms invest in their human capital, train them by polishing their skills and sustain them through an exclusive reward and appraisal system to ensure that firm dynamic capability leads to superior performance (Kryscynski et al., 2021). Firm performance is also based on the effective utilization of resources and their necessary application for enhancing the firm's productivity (Bhagat \& Bolton, 2008). Hence, firms focus on enhancing their innovation capabilities by relying upon dynamic capabilities that ultimately improve their performance. Hence, we can propose that,

H7: Innovation capability mediates the relationship between dynamic capability and firm performance.

\subsection{The mediating role of innovation capability between creativity and competitive advantage}

Creativity has been studied for various industry settings such as technology-based IT firms, manufacturing firms, apparel, and tourism (Pope, 2005). Creativity has been linked to providing higher value to creative assets that utilize creative techniques to innovate (Fasko, 2001). Research suggests that creativity is enhanced through interactivity, openness, and adaptive systems in organizations that enable ease of knowledge sharing among employees and their peers, supervisors, and other company stakeholders (Im \& Workman, 2004). Creativity is also developed through providing various resources, training, and technological systems to the employees that facilitate them in the generation of new ideas (Bharadwaj \& Menon, 2000). Literature also suggests that creativity is promoted through a proper rewards system and recognition to motivate employees to approach things differently in the organization (Fillis \& Rentschler, 2010). Research supports that firms are constantly looking for ways to improve existing processes and introduce new products that enable differentiation compared to their rivals (Runco \& Jaeger, 2012). Creativity has been related to the generation of novel ideas and solutions to existing problems. RBV theory creativity is an intangible, rarely inimitable, and non-substitutable resource that enhances firms' ability to generate competitive advantage (Ruivo et al., 2016).

Creativity is the foundation of innovative activities in the firm, and creativity is based upon actively utilizing the firm's knowledge base (Im \& Workman, 2004). Various studies have linked and associated creativity with a firm's innovation, leading to attaining a firm's competitive advantage (Kaufman et al., 2008; Maley \& Bolitho, 2015). Creativity is suggested to lead to innovation, change management, and business success (Sternberg, 2006). Creativity challenges existing ways and norms to do business and bring a fresh wave to reconsider how business processes are managed and developed across the organization (Zott, 2003). Innovation capability enables firms to manage reorganization easily, link their employees' capabilities with the firm's objectives, and empower employees (Frasson, 2020). Creativity also improves interactivity and collaboration among employees leading to synergy (Bocken \& Geradts, 2020). In contrast, innovation capability allows firms to seek new information, knowledge, and ways to do things (Weerawardena, 2003a). It has been linked to the internal efforts of human, technological, and organizational resources combined with the ability to interact with the external environment to retain resources (Rajapathirana \& Hui, 2018). Hence, we can propose that innovation capability mediates between creativity and competitive advantage.

H8: Innovation capability mediates the relationship between creativity and competitive advantage.

\subsection{The mediating role of innovation capability between creativity and firm performance}

Creativity sets a basic foundation for companies to develop new products and services and even new and improved ways to utilize existing products (Amabile et al., 2005). The previous research suggests that personality, cognitive processes, intrinsic and prosaically motivation, and a sense of meaningful work enable individual creativity (Kaufman, 2016). All these factors differ across individuals in this sense that some likely display more of those factors more than others do. Another study suggested that creativity varies from person to person, despite the dynamics of contextual factors (Fasko, 2001). Therefore, firms develop workplace environments that encourage creativity and activities that polish employees' creative skills and abilities. Firm performance is based upon employees understanding the firms' objectives and goals and exhibiting efforts towards achieving them by doing a little more than expected (Ramani \& Kumar, 2008). Research supports that firm utilizes actions that tap into individual thinking and cognitive abilities such as brainstorming sessions to arrive at creative solutions (Jantunen, 2005).

A firm's performance has also been linked to an achievement or results obtained by management, economics, and marketing, leading to the company's competitiveness, efficiency, and effectiveness (Weerawardena, 2003a). The firm's innovation capability is necessary to align strategic goals to employees' efforts and output (Swink, 2006). Innovation capability help improves employees' skills, knowledge base, and cognitive abilities for approaching various issues in the organization (Bocken \& Geradts, 2020). Information technology, social media networks, and mobile apps make the exchange of information easy and effective between various stakeholders (Stojcic et al., 2018). This provides the basis for various multiple opportunities for firms to introduce their products in creative ways and gain influence in the market ( Anderson \& Gupta, 2009). Firms rely on creativity to sustain existing market share or tap into new niches to increase 
profitability (Zott, 2003). A firm's performance is highly reliant on how human capital is enhanced and utilized for creative solutions for various managerial and operative problems (Dyer, 2006). Innovation capability relies on employees' creativity by constantly polishing and enhancing it to improve firms' performance (Guan \& Ma, 2003). Hence, we can propose that,

H9: Innovation capability mediates the relationship between creativity and firm performance.

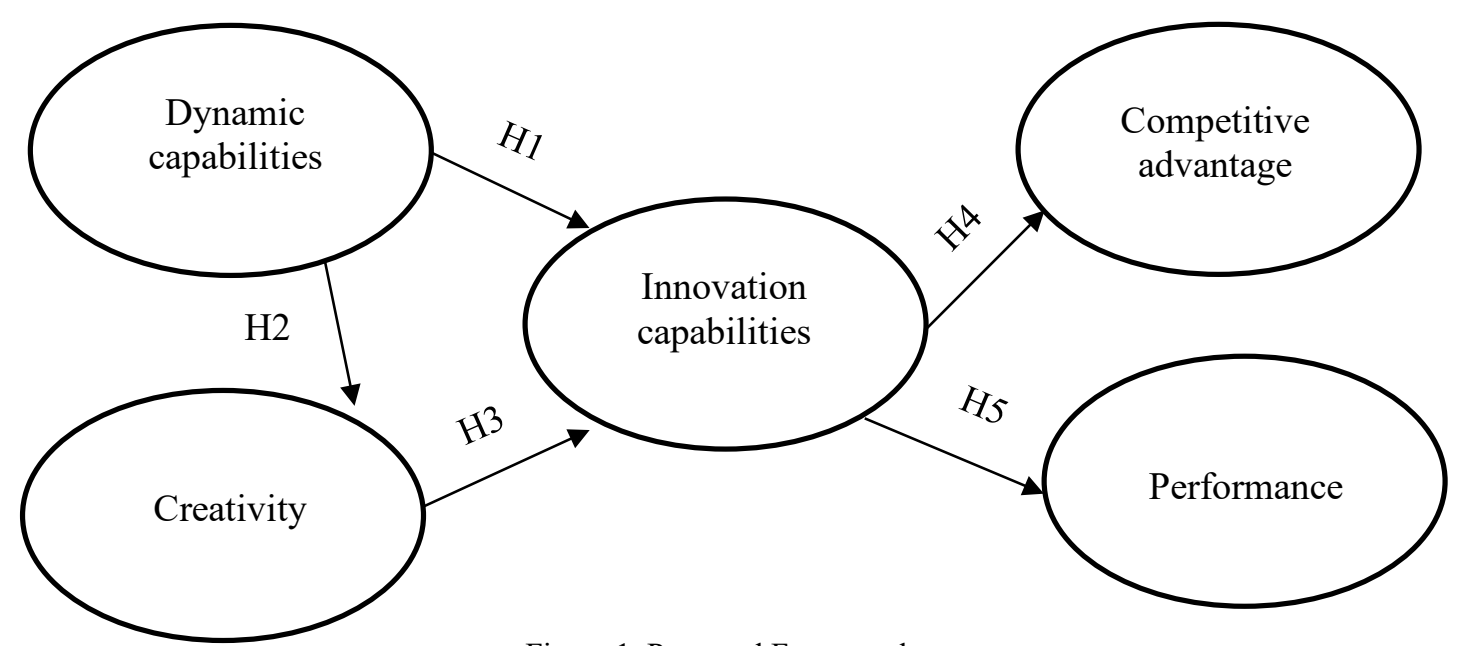

Figure 1. Proposed Framework

\section{Methodology}

This study's methodology is based upon a quantitative online survey. The data is collected from automotive organizations operating in Germany and Italy. Germany is one of the top leading automotive operators in Europe and possesses some of the world's major luxury car companies. The automobile industry of Germany generated around 426 billion euros in total sales in the year 2018 (Eisebith et al., 2021). It supports more than 80,000 jobs and a major contributor to the country's GDP with major Giants being Audi, BMW, Ford, Mercedes-Benz, Porsche, and Volkswagen, all providing the luxurious and highest quality cars customers around the world (Shi, 2020). Whereas the Italian automotive industry dates back to the $1880 \mathrm{~s}$, currently, it is known for supplying small city cars, especially sports-designed cars and supercars. The automotive manufacturing industry in the country is composed of many small and medium-sized (SME) manufacturers and dominated by Fiat, and others including Ferrari, Lamborghini, Maserati, Abarth, and Alfa Romeo (Audasso, 2020). Fiat merged with American Chrysler and became Fiat Chrysler Automobile (FCA) in 2014. According to motor production volume, Italy is the seventh-largest auto-manufacturer in Europe, as observed in 2019. Although in 2019, Italian automotive production experienced $9.3 \%$ decline.

\subsection{Data Collection}

The researcher first contacted various automotive industries in Germany and Italy via phone, email, and Whatsapp to collect data for the study. The administrative department was contacted to obtain permission to survey while explaining the study objectives and purpose. The researcher also provided the confidentiality agreement to utilize study data for this study only and share the study results with the managers, allowing the permission for surveying while maintaining the anonymity of their employees, ensuring privacy. The researcher also provided a sample of a questionnaire for getting the final approval for data collection. The human resource managers then supplied a list of employee email IDs while keeping the names of the employees confidential to reduce bias and any ethical issues from arising. Out of these automotive firms, 4 firms agreed to provide data online through email contacts, including Mercedes-Benz, Ford, Ferrari, and Lamborghini.

After obtaining the employee email id's list, the researcher randomly circulated 800 questionnaires to various employees of the four companies, utilizing random sampling technique by selecting every 2nd employee N-2 on the list provided by the human resource managers that contained employees' email IDs. The decision for using email and an online survey was the geographical distance between the two countries, travel restrictions due to covid-19, the company's policy to maintain the confidentiality of employees, and the low budget and time at hand for the researcher. Also, the online survey provided quick responses with less bias and intervention of the researcher than traditional face-to-face surveys. Most of the employees were unavailable due to work from home restrictions by the government due to the current pandemic. The data was collected using a questionnaire that was divided into two sections. The first section contained information regarding various demographics, including age and gender of employees, type of SME, SME time, Firm size (number of employees). The second section contained latent study variables (dynamic capabilities, creativity, innovation capability, competitive advantage, and performance). The questionnaire was circulated among 800 employees selected randomly from the four firms in December 
2019. The researcher sent soft reminders after three weeks and received 220 filled questionnaires by the first week of January 2020. After that, the employees were sent two reminders after a week, and by the end of the first week of February 2020, the researcher received complete responses of 210 circulated questionnaires at the start of March 2020. In total, 430 complete responses were received, generating a response rate of $53.8 \%$ for circulated 800 initial questionnaires. Out of which 127 were discarded due to incomplete responses, missing values, and outliers. This left the researcher with 303 usable questionnaires.

\subsection{Measures and instruments}

The study constructs were all measured on a Likert scale of $1=$ Strongly Disagree and $5=$ Strongly Agree. The dynamic capability was measured on 5 items containing items related to sensing, seizing, and transforming activities for information utilization in the company for change implementation to operate in a complex environment adopted from (Kump et al., 2019). The creativity construct was measured utilizing 03 items adopted from (Tierney \& Farmer, 2004) that included items regarding the company's expectations of an employee doing work creatively, solving problems, etc. The innovation capability was measured utilizing 03 items adopted from (Panayides, 2006) that included items related to how the company tries new ideas, is creative in operating methods, etc. The competitive advantage was measured using 03 items adopted from (Sigalas et al., 2013) that included exploitation of market opportunities, neutralization of competitive threats, etc. Finally, performance was measured using 03 items adopted from (Panayides, 2006) that measured profitability compared to unit objectives and market share compared to business unit objectives, etc.

\section{Results}

The descriptive statistics for the items and constructs are presented first in this section. Next, a series of scale refining processes were carried out, including tests of object durability, the factorial structure of a group of items, and typical procedure bias. Next, the measurement model's construct validity was examined using convergent and discriminant validity ( Anderson \& Gerbing, 1988). Finally, the structural equation model was subjected to a maximum likelihood analysis to assess the causal relationships proposed in Section 2. The data was analyzed using SPSS 26.0 and SmartPLS 3.3 for Windows.

\subsection{Descriptive}

The descriptive statistics for the items and constructs analyzed are computed and presented in Table 1. A descriptive statistics characterization provides indices for the frequency and percentage of survey data collected.

Table 1: Profile of Respondents

\begin{tabular}{lccc}
\hline Measure & Group & Frequency & Percent \\
\hline \multirow{2}{*}{ Gender } & Female & 87 & 28.7 \\
& Male & 216 & 71.3 \\
Age & $25-35$ & 155 & 51.2 \\
& $36-45$ & 112 & 37.0 \\
Type of SME & $46-55$ & 36 & 11.9 \\
& Partnerships SMEs & 96 & 31.7 \\
& Private limited SMEs & 137 & 45.2 \\
SME Lifespan & Single shareholder SMEs & 70 & 23.1 \\
& Less than 10 years old & 99 & 32.7 \\
& between 10 and 20 years & 105 & 34.7 \\
\multirow{4}{*}{ No. of Employees } & between 20 and 50 years & 83 & 27.4 \\
& more than 50 years & 16 & 5.3 \\
& Fewer than 20 employees & 14 & 4.6 \\
& between 20 and 50 employees & 138 & 45.5 \\
& between 50 and 100 employees & 119 & 39.3 \\
& between 100 and 200 employees & 32 & 10.6 \\
\hline
\end{tabular}

\subsection{Scale refinement}

To evaluate the internal accuracy of the measures, we looked to see if the calculated elements were inter-related. For each of the 5 constructs, Cronbach's alpha coefficients were computed, varied from .701 to .816 , which surpassed the .7 benchmark (Churchill, 1979). It shows that questionnaires have a high degree of internal consistency. Before conducting an exploratory factor study, Bartlett's test of Sphericity and the Kaiser-Meyer-Olkin (KMO) measure of sampling adequacy were computed (Hair et al., 2016). They confirmed the suitability for performing factor analysis, with the statistical findings 
KMO measure $.867>.6$ (Kaiser, 1974). To ensure the factorial consistency of the first-order constructs, exploratory factor analysis was conducted. The findings show that five factors have emerged with the factor loading over .50 .

\subsection{Scale measurement analysis}

The criteria of convergent validity indicate that: as stated by Fornell and Larcker (1981), (1) all the predictor factor loadings for the construct are significant at the $\mathrm{p}<.05$ level, (2) the composite's reliability is greater than .7, and (3) the average variance attributable to the constructs is more than .5. Table 2 reveals that the majority of the loadings are higher than .70. The calculation model was evaluated for discriminating validity using a difference between constructs by extracting their square root mean and root correlation (Fornell \& Larcker, 1981).

Table 2: Reliabilities and Validity

\begin{tabular}{lcccc}
\hline Construct/Items & St. Loadings & $\boldsymbol{\alpha}$ & AVE & CR \\
\hline Dynamic Capability & & .816 & .561 & .861 \\
DC1 & .693 & & & \\
DC2 & .820 & & & \\
DC3 & .704 & & & \\
DC4 & .580 & & & \\
DC5 & .736 & & & \\
Creativity & & .748 & .61 & .824 \\
Cr1 & .739 & & & \\
Cr2 & .704 & & & \\
Cr3 & .738 & & & \\
Innovation Capability & & .789 & .623 & .821 \\
IC1 & .847 & & & \\
IC2 & .852 & & & \\
IC3 & .516 & & & \\
Competitive Advantage & & .701 & .544 & .776 \\
CA1 & .652 & & & \\
CA2 & .754 & & & \\
CA3 & .652 & & & \\
Performance & & .759 & .59 & .794 \\
Per1 & .853 & & & \\
Per2 & .739 & & & \\
Per3 & .783 & & & \\
\hline
\end{tabular}

Table 3 suggests that all discriminant validity values are higher than inter-construct values. Thus, it was concluded that the calculation tools employed in the present investigation could differentiate between constructs.

Table 3: Discriminant Validity

\begin{tabular}{lccccc}
\hline & $\mathbf{1}$ & $\mathbf{2}$ & $\mathbf{3}$ & $\mathbf{4}$ & $\mathbf{5}$ \\
\hline Dynamic Capabilities &. $\mathbf{7 5}$ & & & & \\
Creativity & $.582^{* *}$ & $\mathbf{. 7 8}$ & & & \\
Innovation Capability & $.839^{* *}$ & $.584^{* *}$ & .79 & & \\
Competitive Advantage & $.164^{* *}$ & $.196^{* *}$ & $.153^{* *}$ &. $\mathbf{7 3}$ & \\
Performance & $.308^{* *}$ & $.359^{* *}$ & $.348^{* *}$ & .081 & $\mathbf{. 7 7}$ \\
\hline
\end{tabular}

\subsection{Hypotheses results}

The SmartPLS program was engaged in structural equation modeling of the hypotheses. Table 4 illustrates the findings of the hypothesized relationships. Innovation capability was jointly predicted by dynamic capability $(\beta=.75)$ at the $p<$ .000 significance level, thus supporting $\mathrm{H} 1$ and creativity $(\beta=.466)$ with significance level at $\mathrm{p}<.001$, thus supporting H3. Similarly, the influence of dynamic capability on creativity was significant $(\beta=.509, \mathrm{p}<.000)$ and supporting $\mathrm{H} 2$ with the $25.9 \%$ of the variance in creativity by dynamic capability. Together, these two variables of dynamic capability and creativity accounted for $61.8 \%$ of the variance in innovation capability. Furthermore, innovation capability had a 
significant and direct effect on competitive advantage $\mathrm{H} 4$ with $\beta=.294$ at the $\mathrm{p}<.000$ level and performance $\mathrm{H} 5$ with $\beta=$ .217 at the $\mathrm{p}<.05$ level. Thus, $\mathrm{H} 4$ and $\mathrm{H} 5$ were supported. The amount of variance in competitive advantage was $8.6 \%$, and performance was $4.7 \%$, explained by innovation capability.

The mediation analysis revealed that the innovation capability significantly mediates the relationship between dynamic capability and competitive advantage $(\beta=.221, \mathrm{p}<.001)$ and dynamic capability and performance $(\beta=.163, \mathrm{p}<.05)$, Thus supporting H6 and H7. On the other hand, mediation of innovation capability between creativity, competitive advantage $(\beta=.319, \mathrm{p}<.05)$ and performance $(\beta=.356, \mathrm{p}<.002)$ was also significant providing supports for $\mathrm{H} 8$ and $\mathrm{H} 9$. The detailed finds are presented in Table 4.

Table 4: Hypotheses results

\begin{tabular}{|c|c|c|c|c|c|}
\hline Paths & H1-H9 & ( $\beta)$ & T Statistics & P Values & Results \\
\hline Dynamic Capability -> Innovation Capability & H1 & .751 & 11.039 & .000 & Supported \\
\hline Dynamic Capability -> Creativity & $\mathrm{H} 2$ & .503 & 5.712 & .000 & Supported \\
\hline Creativity -> Innovation Capability & $\mathrm{H} 3$ & .466 & 3.763 & .001 & Supported \\
\hline Innovation Capability -> Competitive advantage & H4 & .294 & 3.635 & .000 & Supported \\
\hline Innovation Capability -> Performance & H5 & .217 & 1.996 & .05 & Supported \\
\hline \multicolumn{6}{|l|}{ Mediation } \\
\hline $\begin{array}{l}\text { Dynamic Capability -> Innovation Capability -> } \\
\text { Competitive Advantage }\end{array}$ & H6 & .221 & 3.301 & .001 & Supported \\
\hline $\begin{array}{l}\text { Dynamic Capability -> Innovation Capability -> } \\
\text { Performance }\end{array}$ & $\mathrm{H} 7$ & .163 & 1.988 & .05 & Supported \\
\hline $\begin{array}{l}\text { Creativity }->\text { Innovation Capability }-> \\
\text { Competitive Advantage }\end{array}$ & H8 & .319 & 2.101 & .05 & Supported \\
\hline $\begin{array}{l}\text { Creativity -> Innovation Capability -> } \\
\text { Performance }\end{array}$ & H9 & .356 & 2.614 & .002 & Supported \\
\hline
\end{tabular}

\section{Discussion}

This study analyzed how a firm achieves competitive advantage and performance levels based upon dynamic capabilities, creativity, and innovation capability. The study setting was the automotive industry, with the data collection occurring for automobile giants operating in Germany and Italy. The companies selected were Ford, Lamborghini, Mercedes Benz, and Ferrari. All these companies are known for providing luxury vehicles worldwide. These are the main source of employment for various people, an asset for technological advancement, economic growth, and financial support for their countries (Analytica, 2021). In addition, these automotive industries are also recognized for processing innovation capabilities and creativity for delivering the best for their customers and stay ahead in the highly complex and competitive market (Eisebith et al., 2021).

The study results show that dynamic capabilities positively impact companies' ability to gain a competitive advantage. The dynamic capabilities were measured for sensing, seizing, and transforming information sources from the internal environment from employees and the external environment from stakeholders such as customers, suppliers, logistics, competitors, media, and government (Bocken \& Geradts, 2020). These dynamic capabilities enable companies to transform their knowledge base to adapt routines that help align with change occurring in a competitive environment. The dynamic capabilities also enable companies to build upon and strategize resources that help them achieve performance goals for individual units and business units by increasing productivity (Suddaby et al., 2020). Thus, companies can adapt and respond to dynamic changes, act upon contingency plans, and progressively survive in the competitive market.

The study results also showed that there is a strong positive association between creativity and competitive advantage. As previous studies also support that creativity is a key ingredient for gaining competitive advantage as creativity enables firms to create new products and services that help increase market share, avoid firms becoming stagnant, and help improve processes to reduce costs (Beaty \& Johnson, 2020). Creativity has almost always been associated with technology use and advancements, but creativity is also critical for employee morale, motivation, and performance (Schutte \& Malouff, 2020). As it helps employees increase their involvement, interest, and excitement towards work. It also increases their commitment to organization performance goals by focusing on problem-solving, contributing affectively towards building new ways of doing things.

Finally, an important contribution of this study was to investigate the role of innovation capability and how it is affected by dynamic capabilities and creativity to achieve performance levels and gain a competitive advantage. There was found to be a positive association between the dynamic capabilities of the firm and innovative capability. As the firm's innovative capability relates to how adequately it utilizes the innovation of its employees, processes, and other systems to continuously improve the way things are managed across the organization (Bocken \& Geradts, 2020). It brings consistency for evolving 
companies' systems and processes to maximize profits and reduce costs (Stojcic et al., 2018). The dynamic capabilities help firms seamlessly align their processes and knowledge management systems to better utilize and improve innovation across the organization's functions.

Then the study results showed that there is a positive association between creativity and innovation capability of the firm. Although innovation and creativity are often used interchangeably, they are different because creativity is the basis for innovation, as creativity is related to imagination. In contrast, innovation is related to implementation (Ismoilov, 2020). Hence, creativity is the generation of new ideas, and innovation capability ensures initiating something new into the market, improving the previous process, and introducing change into relatively stable systems (Liu et al., 2017). Hence, the creativity and innovation ability of the firm are positively related.

Then there was also a positive association between innovation capability and competitive advantage and Firm performance as innovation capability enables firms to identify new ideas and transform them into new or improved products, services, or processes that benefit the firm. It relates to improving firms' resources for discovering opportunities to engage in new product development (Nguyen, 2020). Competitive advantage is based on processing unique resources, skills, or capabilities that enable the firm to stay ahead of its rivals to capture the most market share. Hence, it seriously requires companies to continuously invent and innovate new ways of approaching things that can help them evolve in the marketplace (Yasa et al., 2020). The performance levels of firms are also dependent upon the profitability generated through innovative capabilities, as this helps companies achieve profits and reduce costs. Hence, companies, especially the automotive industry, are looking to provide efficient, cost-effective solutions to meet customers' growing demands while maintaining profitability.

\section{Theoretical contribution}

This study has various theoretical contributions as it investigates antecedents to competitive advantage and performance. The first and foremost contribution is investigating the role of innovation capability, which was studied for the first time as a mediator between dynamic capabilities and competitive advantage, and dynamic capabilities and performance of the company. Researchers can benefit a lot from this study by understanding how innovation capability can help achieve a competitive advantage based on the company's dynamic capabilities through continuously evolving existing systems and processes for improvement and innovation. This study also contributes to understanding how innovation capability mediates between creativity and competitive advantage and performance of the company as this relationship has hardly been studied before. The researchers can examine how innovation capability can help implement creative ideas and skills in the company to reduce costs and improve profitability. Previous studies have investigated performance leading to the company's competitive advantage (Im \& Workman, 2004; García \& Velasco, 2004). This study was unique in investigating its separate role as the dependent variable for being affected by the firm's creativity, dynamic capabilities, and innovation capability. This has not been explored previously. This study is also unique in investigating how dynamic capabilities impact competitive advantage, innovation capability, and firm performance. Researchers can use this study to strengthen their understanding of how a firm's dynamic capabilities help it seize, sense, and transform information to achieve strategic goals for maintaining performance levels and achieving competitive advantage.

\subsection{Practical contributions}

This study has various practical contributions. So, this study was conducted for the automotive industry which is responsible for a huge contribution to exports and GDP of Italy and Germany. Therefore, this study can be highly beneficial for policymakers. In evolving times where sustainability, environmental concerns lead to consuming various products, including automobiles. Companies rely on technologies and innovation to create new products and services that are costeffective, fuel-efficient, and environment-friendly. Companies strongly desire and rely on their knowledge capital to introduce new products, services, and processes to help improve previous products and services. Policymakers can utilize this study to formulate strategies in organizations that help build upon resources that can align and respond to changes occurring in the external environment through relying and building upon their dynamic capabilities. Also, the automotive giants can utilize this study to implement systems and processes that increase and improve the creative skills of their employees so that that idea generation can be promoted. Managers can help use this study to understand how innovation capability can help them take the lead in the market by sustaining their human capital, utilizing information systems, and implementing useful ideas that can help companies improve overall performance and beat their rivals. This study is highly incremental in pointing out that continuously innovating is the recipe for success in any organization regardless of industry setting, firm size, and competition. This company is also vital in helping highlight the resource-based view for companies to build upon their resources, turning them into unique, irreplaceable, and successful assets that help them gain a competitive advantage by staying ahead of others. 


\section{Limitations and future directions}

The first and the foremost limitation of this study was that data was collected during the covid-19 pandemic which led to certain issues such as availability of employees' response rate, as most were working from home, many were laid off, and others were falling victim to the virus. Hence, it created many hurdles in reaching the employees and overall data collection. Therefore, future studies can overcome this limitation by increasing the sample size and opting for offline and online surveys to increase inclusion. The second limitation was that this study focused on the firm's perspective regarding employees' creativity and innovation. In contrast, future studies can be conducted from a customer point of view, and hence, variables such as co-creation and co-innovation can be focused on. Finally, this study also lacked how knowledge management is done to implement innovation and dynamic capabilities of the firm. Hence, future studies can incorporate how knowledge management systems influence creativity and innovation in the organization. 


\section{References}

Amabile, T. M., Barsade, S. G., Mueller, J. S., \& Staw, B. M. (2005). Affect and creativity at work. Administrative science quarterly, 50(3), $367-403$.

Analytica, O. (2021). Biden offers a new impetus for US-German relations. Emerald Expert Briefings

Anderson, A., \& Gupta, P. P. (2009). A cross-country comparison of corporate governance and firm performance: Do financial structure and the legal system matter? Journal of Contemporary Accounting \& Economics, 5(2), 61-79. https://doi.org/https://doi.org/10.1016/i.jcae.2009.06.002

Anderson, J. C., \& Gerbing, D. W. (1988). Structural equation modeling in practice: A review and recommended two-step approach. Psychological Bulletin, 103(3), 411.

Audasso, F. (2020). Innovative financing techniques in automotive market: a pilot project in Italy, Politecnico di Torino].

Beaty, R. E., \& Johnson, D. R. (2020). Automating creativity assessment with SemDis: An open platform for computing semantic distance. Behavior research methods, 1-24.

Belderbos, R., Carree, M., \& Lokshin, B. (2004). Cooperative R\&D and firm performance. Research Policy, 33(10), 1477-1492. https://doi.org/https://doi.org/10.1016/j.respol.2004.07.003

Bhagat, S., \& Bolton, B. (2008). Corporate governance and firm performance. Journal of Corporate Finance, 14(3), 257-273. https://doi.org/https://doi.org/10.1016/j.jcorpfin.2008.03.006

Bharadwaj, S., \& Menon, A. (2000). Making Innovation Happen in Organizations: Individual Creativity Mechanisms, Organizational Creativity Mechanisms, or Both? Journal of Product Innovation and Management, 17(6), 424-434. https://doi.org/https://doi.org/10.1111/1540-5885.1760424

Bocken, N. M., \& Geradts, T. H. (2020). Barriers and drivers to sustainable business model innovation: Organization design and dynamic capabilities. Long Range Planning, 53(4), 101950.

Bowman, C., \& Ambrosini, V. (2003). How the resource-based and the dynamic capability views of the firm inform corporate-level strategy. British journal of management, 14(4), 289-303.

Cavusgil, S. T., Calantone, R. J., \& Zhao, Y. (2003). Tacit knowledge transfer and firm innovation capability. Journal of business industrial marketing, 18(1), 6-21.

Chivandi, A., Samuel, O., \& Muchie, M. (2020). African cultures as tourism innovative capability in South African tourism sector: a Gauteng Province perspective. GeoJournal of Tourism Geosites, 30(Suppl. 2), 917-925.

Churchill, G. A. (1979). A paradigm for developing better measures of marketing constructs. Journal of Marketing Research, 16(1), 64-73.

Cockburn, I. M., Henderson, R. M., \& Stern, S. (2000). Untangling the origins of competitive advantage. Strategic management journal, 21(10-11), 1123-1145.

Danneels, E. (2011). Trying to become a different type of company: Dynamic capability at Smith Corona. Strategic management journal, $32(1), 1-31$

Duarte, A., Gomes, D., \& das Neves, J. G. (2014). Tell me your socially responsible practices, I will tell you how attractive for recruitment you are! The impact of perceived CSR on organizational attractiveness. Tékhne, 12, 22-29.

Fasko, D. (2001). Education and creativity. Creativity research journal, 13(3-4), 317-327.

FILLIS, I., \& RENTSCHLER, R. (2010). THE ROLE OF CREATIVITY IN ENTREPRENEURSHIP. Journal of Enterprising Culture, 18(01), 49-81. https://doi.org/10.1142/s0218495810000501

Fornell, C., \& Larcker, D. F. (1981). Evaluating structural equation models with unobservable variables and measurement error. Journal of marketing research, 18(1), 39-50.

Frasson, A. (2020). Mobility Demand: from Ownership to Fruition How the Change in the Demand Has Shaped and Is Still Challenging the Last Decade Automotive Industry in Italy, Università Ca'Foscari Venezia].

Fromhold-Eisebith, M., Marschall, P., Peters, R., \& Thomes, P. (2021). Torn between digitized future and context-dependent past-How implementing 'Industry 4.0 'production technologies could transform the German textile industry. Technological Forecasting Social Change, 166, 120620.

Galbreath, J. (2005). Which resources matter the most to firm success? An exploratory study of resource-based theory. Technovation, 25(9), 979-987.

Gibb Dyer, W. (2006). Examining the "Family Effect" on Firm Performance. Family Business Review, 19(4), 253-273. https://doi.org/10.1111/j.1741-6248.2006.00074.x

Gisip, I., \& Harun, H. (2013). An assessment of government support programs in the development of SMEs in Malaysia: Issues and challenges. Scottish Journal of Arts, Social Sciences and Scientific Studies, 8(2), 9-18.

Gong, Y., Zhou, J., \& Chang, S. (2013). Core Knowledge Employee Creativity and Firm Performance: The Moderating Role of Riskiness Orientation, Firm Size, and Realized Absorptive Capacity. 66(2), 443-482. https://doi.org/https://doi.org/10.1111/peps.12024

Guan, J., \& Ma, N. (2003). Innovative capability and export performance of Chinese firms. Technovation, 23(9), 737-747. https://doi.org/https://doi.org/10.1016/S0166-4972(02)00013-5

Gunday, G., Ulusoy, G., Kilic, K., \& Alpkan, L. (2011). Effects of innovation types on firm performance. International Journal of Production Economics, 133(2), 662-676. https://doi.org/https://doi.org/10.1016/j.ijpe.2011.05.014

Hagiu, A., \& Wright, J. (2020). Data-enabled learning, network effects, and competitive advantage (working paper.

Hair, J. F., Hult, G. T. M., Ringle, C., \& Sarstedt, M. (2016). A Primer on Partial Least Squares Structural Equation Modeling (PLS-SEM). Sage.

Haldma, T., Näsi, S., Grossi, G., Saunila, M., \& Ukko, J. (2012). A conceptual framework for the measurement of innovation capability and its effects. Baltic Journal of Management, 7(4), 353-375.

Hanelt, A., Firk, S., Hildebrandt, B., \& Kolbe, L. M. (2021). Digital M\&A, digital innovation, and firm performance: an empirical investigation. European Journal of Information Systems, 30(1), 3-26.

Helfat, C. E. (1997). Know-how and asset complementarity and dynamic capability accumulation: the case of R\&D. Strategic management journal, 18(5), 339-360.

Hinterhuber, A. (2013). Can competitive advantage be predicted? Management Decision, 51(4), 795-812.

Iansiti, M., \& Clark, K. B. (1994). Integration and dynamic capability: evidence from product development in automobiles and mainframe computers. Industrial and Corporate Change, 3(3), 557-605.

Im, S., \& Workman, J. P. (2004). Market Orientation, Creativity, and New Product Performance in High-Technology Firms. Journal of Marketing, 68(2), 114-132. https://doi.org/10.1509/jmkg.68.2.114.27788

Ireland, R. D., Hitt, M. A., \& Vaidyanath, D. (2002). Alliance management as a source of competitive advantage. Journal of Management, 28(3), 413-446.

Ismoilov, T. (2020). Cognitive-Psychological Diagram of processes Of Scientific And Technical Creativity Of Students. JSPI Scientific Publication Archive, 14(1). 
Jabri, U., Elihami, E., \& Ibrahim, I. (2020). The effects of approach instruction on student's reading performance. Jurnal Edukasi Nonformal, $1(1), 72-80$.

Jantunen, A. (2005). Knowledge-processing capabilities and innovative performance: an empirical study. European Journal of Innovation Management, 8(3), 336-349. https://doi.org/10.1108/14601060510610199

Kaiser, H. F. (1974). An index of factorial simplicity. Psychometrika, 39(1), 31-36.

Kaufman, B. E. (2015). The RBV theory foundation of strategic HRM: critical flaws, problems for research and practice, and an alternative economics paradigm. Human Resource Management, 25(4), 516-540. https://doi.org/https://doi.org/10.1111/1748-8583.12085

Kaufman, J. C. (2016). Creativity 101. Springer publishing company.

Kaufman, J. C., Plucker, J. A., \& Baer, J. (2008). Essentials of creativity assessment (Vol. 53). John Wiley \& Sons.

Khana, M. P., Talibb, N. A., \& Kowangc, T. O. (2020). The development of a sustainability framework via lean green six sigma practices in SMEs based upon RBV theory. Development, 12(5), 135-156.

Kryscynski, D., Coff, R., \& Campbell, B. (2021). Charting a path between firm-specific incentives and human capital-based competitive advantage. Strategic Management Journal, 42(2), 386-412.

Kump, B., Engelmann, A., Kessler, A., \& Schweiger, C. (2019). Toward a dynamic capabilities scale: measuring organizational sensing, seizing, and transforming capacities. Industrial Corporate Change, 28(5), 1149-1172.

Lawson, B., \& Samson, D. (2001). Developing innovation capability in organizations: a dynamic capabilities approach. International journal of innovation management, 5(03), 377-400.

Lin, Y., \& Wu, L.-Y. (2014). Exploring the role of dynamic capabilities in firm performance under the resource-based view framework. Journal of business research, 67(3), 407-413.

Liu, D., Gong, Y., Zhou, J., \& Huang, J.-C. (2017). Human Resource Systems, Employee Creativity, and Firm Innovation: The Moderating Role of Firm Ownership. Academy of Management Journal, 60(3), 1164-1188. https://doi.org/10.5465/amj.2015.0230

Makadok, R. (2001). Toward a synthesis of the resource-based and dynamic-capability views of rent creation. Strategic management journal, 22(5), 387-401.

Maley, A., \& Bolitho, R. (2015). Creativity. ELT Journal, 69(4), 434-436.

Menguc, B., \& Auh, S. (2006). Creating a Firm-Level Dynamic Capability through Capitalizing on Market Orientation and Innovativeness. Journal of the Academy of Marketing Science, 34(1), 63-73. https://doi.org/10.1177/0092070305281090

Miotto, G., Del-Castillo-Feito, C., \& Blanco-González, A. (2020). Reputation and legitimacy: Key factors for Higher Education Institutions' sustained competitive advantage. Journal of Business Research, 112, 342-353.

Newbert, S. L. (2005). New firm formation: A dynamic capability perspective. Journal of small business management, 43(1), 55-77.

Nguyen, D. T. T. (2020). An empirical study on the impact of sustainability reporting on firm value. Journal of Competitiveness, 12(3), 119135 .

Nukunudompanich, M., Budiutama, G., Suzuki, K., Hasegawa, K., \& Ihara, M. (2020). The dominant effect of the grain size of the MAPbI 3 perovskite is controlled by the surface roughness of TiO 2 on the performance of perovskite solar cells. CrystEngComm, 22(16), 2718-2727.

O'Connor, G. C. (2008). Major innovation as a dynamic capability: A systems approach. Journal of product innovation management, 25(4), 313-330.

O'Reilly III, C. A., \& Tushman, M. L. (2008). Ambidexterity as a dynamic capability: Resolving the innovator's dilemma. Research in organizational behavior, 28, 185-206.

Panayides, P. (2006). Enhancing innovation capability through relationship management and implications for performance. European Journal of Innovation Management, 9(4), 466-483.

Pope, R. (2005). Creativity: Theory, history, practice. Psychology Press.

Porter, M. E., \& Kramer, M. R. (2002). The competitive advantage of corporate (Readings in Strategic Management. Amazon.

Quintana-García, C., \& Benavides-Velasco, C. A. (2004). Cooperation, competition, and innovative capability: a panel data of European dedicated biotechnology firms. Technovation, 24(12), 927-938. https://doi.org/https://doi.org/10.1016/S0166-4972(03)00060-9

Rajapathirana, R. J., \& Hui, Y. (2018). Relationship between innovation capability, innovation type, and firm performance. Journal of Innovation Knowledge, 3(1), 44-55.

Ramani, G., \& Kumar, V. (2008). Interaction Orientation and Firm Performance. Journal of Marketing, 72(1), 27-45. https://doi.org/10.1509/jmkg.72.1.027

Ruivo, P., Rodrigues, J., Johansson, B., Oliveira, T., \& Rebelo, J. (2016). Using TOE and RBV theories to define a theoretical model to assess ERP value across Iberian Manufacturing and Services SMEs. Procedia Computer Science, 100, 474-479.

Runco, M. A., \& Jaeger, G. J. (2012). The standard definition of creativity. Creativity research journal, 24(1), 92-96.

Sanchez, R. (2008). A scientific critique of the resource-based view (RBV) in strategy theory, with competence-based remedies for the RBV's conceptual deficiencies and logic problems. In R. Sanchez (Ed.), A Focused Issue on Fundamental Issues in Competence Theory Development (Vol. 4, pp. 3-78). Emerald Group Publishing Limited. https://doi.org/10.1016/S1744-2117(08)04001-2

Schutte, N. S., \& Malouff, J. M. (2020). Connections between curiosity, flow, and creativity. Personality Individual Differences, 152 , 109555.

Sher, P. J., \& Yang, P. Y. (2005). The effects of innovative capabilities and R\&D clustering on firm performance: the evidence of Taiwan's semiconductor industry. Technovation, 25(1), 33-43. https://doi.org/https://doi.org/10.1016/S0166-4972(03)00068-3

Shi, S. (2020). German-Chinese Economic Relations in the Present: Opportunities and Challenges (China's New Silk Road Dreams (pp. 51).

Sigalas, C., Economou, V. P., \& Georgopoulos, N. B. (2013). Developing a measure of competitive advantage. Journal of Strategy Management, 6(4), 320-342.

Slater, S. F., Mohr, J. J., \& Sengupta, S. (2014). Radical product innovation capability: Literature review, synthesis, and illustrative research propositions. Journal of Product Innovation Management, 31(3), 552-566.

Somsuk, N., Laosirihongthong, T., \& McLean, M. W. (2012, 11-13 June 2012). Strategic management of university business incubators (UBIs): Resource-based view (RBV) theory. (Ed.), ${ }^{\wedge}$ (Eds.). 2012 IEEE International Conference on Management of Innovation \& Technology (ICMIT).

Sternberg, R. J. (2006). The nature of creativity. Creativity research journal, 18(1), 87.

Stojcic, N., Hashi, I., \& Orlic, E. (2018). Creativity, innovation effectiveness, and productive efficiency in the UK. European Journal of Innovation Management, 21(4), 564-580. https://doi.org/10.1108/EJIM-11-2017-0166

Suddaby, R., Coraiola, D., Harvey, C., \& Foster, W. (2020). History and the micro-foundations of dynamic capabilities. Strategic Management Journal, 41(3), 530-556.

Swink, M. (2006). Building collaborative innovation capability. Research-technology management, 49(2), 37-47.

Tierney, P., \& Farmer, S. M. (2004). The Pygmalion process and employee creativity. Journal of Management, 30(3), $413-432$.

Tseng, S.-M., \& Lee, P.-S. (2014). The effect of knowledge management capability and dynamic capability on organizational performance. Journal of Enterprise Information Management, 27(2), 158-179.

Vogel, R., \& Güttel, W. H. (2013). The dynamic capability view in strategic management: A bibliometric review. International Journal of 
Management Reviews, 15(4), 426-446

Wang, D.-J., Lv, H.-J., \& Zhou, Y.-T. (2021). The curvilinear relationship between advice-giving and innovative capability: a knowledge exchange and combination explanation of the moderated relations. Chinese Management Studies, 15(2), 413-427.

Weerawardena, J. (2003a). Exploring the role of market learning capability in competitive strategy. European Journal of Marketing, 37(3/4), 407-429. https://doi.org/10.1108/03090560310459023

Weerawardena, J. (2003b). The role of marketing capability in innovation-based competitive strategy. Journal of Strategic Marketing, 11(1), 15-35. https://doi.org/10.1080/0965254032000096766

Yasa, N., Giantari, I., Setini, M., \& Rahmayanti, P. (2020). The role of competitive advantage in mediating the effect of promotional strategy on marketing performance. Management Science Letters, 10(12), 2845-2848.

Zott, C. (2003). Dynamic capabilities and the emergence of interindustry differential firm performance: insights from a simulation study. Strategic Management Journal, 24(2), 97-125. https://doi.org/https://doi.org/10.1002/smj.288 